\title{
LOS SESGOS COGNITIVOS Y SU INFLUJO EN LA DECISIÓN JUDICIAL. APORTES DE LA PSICOLOGÍA JURÍDICA A LOS PROCESOS PENALES DE CORTE ACUSATORIO
}

\author{
Paola Iliana De la Rosa Rodríguez* \\ Victor David Sandoval Navarro**
}

\begin{abstract}
Resumen: El propósito de este trabajo es hacer disponible a los actores jurídicos y a la sociedad el conocimiento sobre los procesos psicológicos imbuidos en la toma de decisiones del actor judicial, en razón de que este no únicamente está guiado por la ley y por el derecho, sino también por ideas preconcebidas
\end{abstract}

* Fecha de recepción: 14 de marzo de 2016. Fecha de modificación: 23 de marzo de 2016. Fecha de aceptación: 24 de junio de 2016. Para citar el articulo: De la Rosa RodríGuez, PAOLA y SANDOVAL, VÍCTOR DAVID (2016). "Los sesgos cognitivos y su influjo en la decisión judicial. Aportes de la psicología jurídica a los procesos penales de corte acusatorio", en Revista Derecho Penal y Criminología, Vol. 38, n. ${ }^{\circ}$ 102, enero-junio de 2016. Bogotá: Universidad Externado de Colombia, pp. 141-164. DOI: http://dx.doi.org/10.18601/ 01210483.v37n102.08

** Abogada, profesora-investigadora de la Facultad de Derecho de la Benemérita Universidad Autónoma de San Luis Potosí, México. Doctora por la Universidad Autónoma de Nayarit, México. Maestría en abogacía con énfasis en juicios orales por Southwestern University Lawschool. Maestría en Derecho internacional por Instituto Tecnológico de Estudios Superiores de Monterrey. San Luis Potosí, México. E-mail: paola.delarosa@uaslp.mx

*** Abogado, maestría en Criminología y Ciencias Forenses Universidad Autónoma de Tamaulipas - UAMrA, Reynosa, Tamaulipas México. Cursando actualmente licenciatura en psicología por Universidad Autónoma de San Luis Potosí, México. Profesor auxiliar en prácticas profesionales en psicología forense, Facultad de Psicología, UASLP. Psicólogo auxiliar en atención a víctimas del delito en la Procuraduría General de Justicia del Estado de San Luís Potosí, S.L.P. Tamaulipas, México. E-mail: a2153718012@alumnos.uat.edu.mx. 
y valores en los que se fundamenta su concepción del mundo. De ahí que valga cuestionarse cuánta es la convicción personal del juzgador acerca de la ocurrencia de los hechos, qué motiva su decisión o en qué medida sus propias proyecciones, aversiones o la opinión pública inciden en la decisión judicial. Con esta intención se analiza el rol que desempeña el juez en el proceso penal acusatorio, distinguiendo el rol del juzgador con sistemas de corte inquisitivo, y específicamente se hace referencia al modelo de justicia en México. También se hace una crítica a las categorizaciones que se han hecho del funcionario judicial y se exponen asimismo los estímulos y circunstancias que influyen en el juez, aspectos que son estudiados por la psicología. Finalmente, se hace una clasificación de los mencionados sesgos, concluyendo que tomar conciencia de ello ayudará al funcionario judicial a asumir mayor imparcialidad en sus sentencias.

Palabras clave: Psicología jurídica; Labor judicial; Sesgos cognitivos; Sistema acusatorio; Sentencia judicial.

\title{
THE INFLUENCE OF COGNITIVE BIASES ON COURT DECISIONS. CONTRIBUTIONS OF LEGAL PSYCHOLOGY TO THE ADVERSARY CRIMINAL PROCEEDINGS
}

\begin{abstract}
The purpose of this paper is to disperse among the judiciary and society the psychological procedures involved in the decision-making process of judges since they are not only influenced by law but by previous ideas and values. It is worth questioning: in what extent their personal views and beliefs are the bases of verdicts? How can aversions and public opinion have an impact in the court decision?

This paper analyzes and states the differences of the judicial role in the Mexican adversarial system and the inquisitorial models of justice. It also critiques the categories of the judicial officers and presents the circumstances that make an impact on judicial decisions, according to Psychology studies. It finally classifies cognitive biases and concludes that the more knowledge judges have about it, the more imparcial judgments will be.

Keywords: Legal Psychology; Judicial Work; Criminal Procedure; Cognitive Biases; Adversarial System; Court Decision.
\end{abstract}

\section{INTRODUCCIÓN}

El modelo de justicia de corte advesarial contempla la figura de un juzgador de hechos imparcial, quien resuelve las disputas con base en la información que provean las partes durante un procedimiento formal, conociendo directamente y escuchando de viva voz a los implicados del asunto. Este contacto o aproximación trae consigo nuevos retos para quien imparte justicia, pues el órgano jurisdiccional se convence 
no únicamente en base a lo ocurrido en la audiencia y lo alegado por las partes, sino que existen otros factores que son determinantes en la elaboración de su resolución. Se trata de procedimientos mentales que todos los seres humanos llevamos a cabo cuando percibimos, analizamos y actuamos en una determinada situación.

\section{EL PAPEL DEL JUEZ EN EL SISTEMA PENAL ACUSATORIO}

El nuevo modelo de justicia definido en la constitución proyecta una nueva figura del juzgador. De hecho, el esquema democrático en el cual se gesta el proceso penal acusatorio hace menester la figura de un juez que pueda entender y responder a la realidad de la sociedad en la cual se desempeña en el entendido de que con su sentencia el juez puede dar lugar a una norma jurídica individualizada que supera la normatividad con la que juzga (ROCHA LicEA, 2014, pp. 65-90).

Para analizar el procedimiento penal acusatorio mexicano nos remitimos a la norma procesal única en la República, el Código Nacional de Procedimientos, en lo sucesivo CNPP. Este cuerpo normativo asigna a cada participante actividades específicas y detalladas, siendo así que la más alta encomienda corresponde al juez, actor último en quien deberá descansar la responsabilidad de emitir una sentencia. En este contexto, el CNPP contempla un órgano jurisdiccional garante del debido proceso y protector de los derechos fundamentales de las partes ${ }^{1}$. Se estipula que el funcionario tiene que pronunciarse respecto de las pretensiones de las partes durante la audiencia y que ha de fundar y motivar todas sus resoluciones. Como dijera LUIS PÁSARA, "la obligación de motivar corresponde a una concepción democrática del poder, que otorga al juez una facultad y una obligación inseparables: tienes el poder de decidir, pero tienes el deber de justificar tu decisión" (PÁSARA, 2012, p. 36).

Por lo general, las diligencias que enmarca el CNPP para el órgano jurisdiccional distinguen su actuación de aquella que tuvo en un modelo inquisitivo; los principios rectores orientan el desahogo de las audiencias al mismo tiempo que sitúan al órgano jurisdiccional como figura preponderante, pues está obligado a conocer el caso de manera presencial y directa. Es sobre referidos principios que se sustenta la actuación de los sujetos procesales, los cuales se constituyen a su vez para fortalecer la legalidad en la búsqueda de la verdad y contribuyen a la restauración de la confianza social de un sistema de impartición de justicia que arrastra los vestigios del sistema tradicional.

Si bien en el sistema inquisitivo los procesos de toma de decisiones judiciales eran ajenos a los ciudadanos, la transparencia del modelo penal acusatorio hace posible y obliga a cuestionarnos respecto de las maneras y las causas por las que un juez

1 Artículos $10,11,12,18$ y 134 CNPP. 
llega a las conclusiones que motivaron su sentencia. Del mismo modo, la publicidad, oralidad, contradictoriedad e inmediación con que se perfilan las audiencias del nuevo esquema exigen un cambio en la forma de procesamiento, que implica que el juzgador resuelva en ese mismo instante problemas, apoyándose con la información que se haya incorporado y le hayan proporcionado las partes y justificando las razones de su decisión.

Bajo este esquema, el funcionario judicial debe tener capacidad para absorber y asimilar la mayor información posible y discriminar la que no sea relevante; asimismo, debe enarbolar sus capacidades argumentativas y de interpretación. Para ello, en su labor, el juez debe poseer una actitud crítica respecto de la información que le es expuesta por las partes. Además, dentro de un procedimiento que se desarrolla en base a audiencias públicas, orales y concentradas, el juzgador no tiene oportunidad de tomarse varios días para consultar sus códigos, sino que dependerá únicamente del andamiaje de conocimientos que posea para responder a las situaciones e incidencias que se le presenten, de tal manera que en sus decisiones domine la dogmática jurídico-penal respectiva (RoCHA LICEA, ob cit., pp. 66 y ss.). En consonancia con lo anterior, el CNPP impone a dicho funcionario judicial la obligación de resolver todas las peticiones y planteamientos de las partes de manera inmediata y directa en audiencia pública ${ }^{2}$.

En este orden de ideas, la dinámica de las audiencias en este sistema obliga a que el juzgador tenga capacidades de dirección. De acuerdo con ello, el cNPP señala que “el juzgador que preside la audiencia de juicio ordenará y autorizará las lecturas pertinentes, hará las advertencias que correspondan, tomará las protestas legales y moderará la discusión; impedirá intervenciones impertinentes o que no resulten admisibles, sin coartar por ello el ejercicio de la persecución penal o la libertad de defensa" 3 . Además, debe de ser una persona cercana al justiciable y salvaguardar el debido cumplimiento de un debido proceso (GARCía BAEZA, 2014, p. 9). Aunado a ello, atendiendo a la probidad, el funcionario judicial procurará que en todo momento se respete la regularidad del procedimiento, el ejercicio de las facultades o derechos en términos de ley y la buena $\mathrm{fe}^{4}$.

Entre otras encomiendas y de acuerdo al principio de inmediación,--el cual requiere que la prueba tenga un contacto directo con el juez,- el tribunal de enjuiciamiento que presida la audiencia de debate, escuchará los alegatos de los representantes jurídicos y las declaraciones de los testigos. En efecto, es ante este que se realiza la rendición y el análisis de la prueba, y de acuerdo con el cercioramiento que adquiera respecto de los planteamientos sometidos a su consideración, manifestará a las par-

\footnotetext{
2 Artículo 52 del CNPP.

3 Artículo 354 del CNPP.

4 Artículo 107 CNPP.
} 
tes el valor que otorgó a cada uno de los indicios existentes para ello, absolviendo o condenando al acusado.

Una vez estudiado el nuevo papel del juzgador en México y siguiendo nuestro propósito de determinar las motivaciones que se albergan en el juez para tomar una determinada decisión en cada litigio, advertimos la importancia de dilucidar el desempeño del órgano jurisdiccional en la apreciación probatoria en el sistema acusatorio, siendo que el juez fincará su resolución en la evaluación de los medios de convicción que le presenten. Lo anterior exige abordar el sistema de valoración de la prueba por lo que anotamos que valorar la prueba es una actividad intelectual que realiza el órgano jurisdiccional a fin de conocer la verdad. Se trata de una valoración lógica, que implica un análisis razonado de los hechos y las pruebas que, lógicamente, conducen a una conclusión. Es así que, al evaluar los medios de convicción, el juez apreciará en conciencia el valor de los indicios o datos probatorios hasta poder considerarlos como prueba plena. Coincidimos con FLORENCIO MIXÁN cuando expresa que "la valoración de la prueba como una condición del debido proceso requiere que ese acto cognoscitivo sea integral, metódico, libre, razonado e imparcial, que refleje independencia de criterio al servicio de la solución justa del caso" (MiXán Mass, 1991,p. 134)

De acuerdo con este modelo, el juez que va a resolver tiene libertad para conceder o negar valor probatorio a los elementos probatorios que son desahogados de conformidad con las reglas establecidas en la ley. Mencionada libertad solamente se encuentra condicionada por la norma que exige que los medios de prueba sean excluidos para la audiencia del debate, en caso de tener efectos dilatorios, haberse obtenido con violación a derechos fundamentales, haber sido declaradas nulas, o que contravengan las disposiciones señaladas en la ley para su desahogo ${ }^{5}$. Es menester mencionar que, en el sistema de libre apreciación de la prueba, el juez no obedece a un criterio legal preestablecido, sino que resuelve según lo que le dicta su propia estimación; en pocas palabras, no es la ley la que fija el valor de la prueba, es el mismo juzgador quien lo hace. De conformidad con lo anterior, el CNPP dispone que las pruebas serán valoradas por el órgano jurisdiccional de manera libre y lógica ${ }^{6}$.

Es así que el tribunal apreciará las probanzas extraídas de la totalidad del debate y les asignará el valor correspondiente a cada uno de los elementos de prueba, con la aplicación estricta de las reglas de la sana crítica, es decir, observando las reglas de la lógica, los conocimientos científicos y las máximas de la experiencia. Ahora bien, el modelo penal acusatorio requiere de una mayor rigurosidad metodológica y científica y, en palabras de VERA VEGA (2011,pp. 118-119):

5 Artículo 346 CNPP.

6 Artículo 259 CNPP. 
"La búsqueda de la verdad constituye una condición de legitimidad para el mismo [proceso] pues en su carácter de instancia concebida para la administración de justicia, solo en la medida de que actúe impulsado por una finalidad de esta envergadura, las decisiones resultantes (sentencias de los tribunales) estarán en condiciones de cumplir con los estándares de corrección, validez y aceptabilidad que impone la sujeción a un estado de derecho".

Bajo esta tesitura, es importante señalar que el funcionario judicial, como individuo, queda expuesto a una infinita cantidad de estímulos que escapan de su conocimiento profesional y empírico, no obstante inciden en la toma de decisiones que afectan los intereses de un individuo y, al mismo tiempo, sientan precedente en la comunidad. Estos estímulos resultan ajenos al estudio del derecho, ya que propiamente pertenecen al área de la psicología; de ahí los aportes que hace esta última al campo del derecho y, en consecuencia, la creación de la Psicología Jurídica reconocida como disciplina.

\section{LA PSICOLOGÍA JURÍDICA Y SU UTILIDAD}

Creemos pertinente en esta etapa de nuestro estudio subrayar la importancia y utilidad de la Psicología Jurídica. Como dato preliminar, anotamos que es a partir de finales del siglo XX y comienzos del siglo XXI cuando los estudios de la Psicología y la Criminología se unen conformándose la Psicología Criminal, que derivará en otras ramas como Psicología Jurídica (Velasco DíAz, 2014, p. 2).

Clemente define la Psicología Jurídica como "el estudio del comportamiento de las personas y de los grupos en cuanto que tienen la necesidad de desenvolverse dentro de ambientes regulados jurídicamente, así como de la evolución de dichas regulaciones jurídicas o leyes en cuanto que los grupos sociales se desenvuelven en ellas" (DíAZ, 2010, p. 12). Beltrán y Vargas la entienden como la encargada de los problemas relacionados con el comportamiento humano y que surgen en el sistema jurídico legal, siendo aplicables a la policía, los tribunales, las correccionales para infractores e instituciones carcelarias y penitenciarias, entre otros (BELTRÁN, E. y VArgas, N., 1993, pp. 421-438.). Por su parte, Morales y García LóPez (2010, p. 239) la han definido como el área de la psicología encargada de describir, explicar, predecir e intervenir sobre el comportamiento humano que tiene lugar en el contexto jurídico, con la finalidad de contribuir a la construcción y práctica de sistemas jurídicos objetivos y justos.

En este sentido, el contexto jurídico abre una gama de acción a la psicología, en donde esta puede aportar en ámbitos legislativos, administrativos o en que se imparta justicia, por lo que, para un adecuado entendimiento de la Psicología Jurídica, se la considerará como la ciencia constituyente de las psicologías aplicadas a la adminis- 
tración e impartición de justicia -forense, criminal, penitenciaria, etc. $-{ }^{7}$.Aducimos, entonces, que en este documento la Psicología Jurídica se considerará como la rama de la Psicología que analiza los procesos cognoscitivos y emocionales, no fácilmente observables, así como las creencias y actitudes del órgano jurisdiccional, siendo este un conocimiento que se aplica para el mejor ejercicio del derecho. Bajo esta tesitura, la investigación psicológica puede ofrecer un valor fundamental para los sistemas de justicia y para la sociedad al ofrecer mayor precisión científica y entendimiento en relación a las maneras más efectivas en que las dinámicas psicológicas se vean involucradas en el sistema de justicia.

La mencionada disciplina se ha ido consolidando en un cuerpo organizado de conocimientos, con un uso cada vez más frecuente del método científico (ídem, pp. 237 y ss.). Este desarrollo ha obedecido a lo necesario que resulta su intervención en ambientes jurídicos. Es así que en nuestros días los psicólogos están inmersos en la impartición de justicia ya sea en juzgados, en academias policiacas, en servicios periciales o en penitenciarias, por mencionar algunos. Al llevar a cabo su trabajo de manera crítica, profesional y científica, pueden enaltecer su labor y contribuir en forma propositiva en la administración de justicia.

Con referencia a las actividades con que la ciencia de la psicología puede enriquecer los ámbitos jurídicos, la misma norma adjetiva penal constituye una puerta de entrada a actividades relacionadas con el análisis y síntesis de información, la empatía con el justiciable, la valoración de pruebas, el análisis razonado y la toma de conciencia en las que es prudente y pertinente el apoyo de un psicólogo; no como un personaje que decida por un funcionario, sino como un soporte en el que pueda apoyarse y que brinde la posibilidad de cuestionarse a sí mismo si la valoración de las pruebas, por ejemplo, se hizo tomando en cuenta las particularidades de la "sana crítica" o bien, si se encuentra influenciada por motivaciones, razonamientos o prejuicios propios.

Una vez establecidos los conceptos que anteceden, anotamos que una de las contribuciones que hace el área de la psicología en el entorno jurídico se refiere al estudio de los procesos mentales que se llevan a cabo para emitir resoluciones judiciales, pues se considera que estas últimas se encuentran infiltradas de intuiciones subjetivas, sentimientos o ideas preconcebidas. Desde esta perspectiva, aunque el razonamiento del juez queda vinculado y delimitado por la ley, el funcionario judicial no únicamente se guiará por la norma y el Derecho, sino por otras causas que interfieren en su toma de decisiones y que están en los campos de la lógica y de las ciencias del comportamiento. El juez, además de tomar en cuenta el tipo de delito juzgado, las

7 Y así como la Psicología Forense alude a asuntos referentes al foro, la criminal al estudio de las causas de la comisión de crímenes en sujetos y la psicología penitenciaria al trabajo readaptativo, la Psicología Jurídica tendrá como objeto de estudio a los actores del procedimiento penal y particularmente al órgano jurisdiccional. 
condenas previas o la edad del acusado, tendrá en consideración su propio contexto y vivencias, e incluso evaluará el impacto que la sentencia producirá sobre la sociedad. Lo anterior merece atender el proceso cognitivo humano, específicamente aquel que se lleva a cabo en la labor del actor judicial.

El juzgador primero decide y luego razona. Dicho sea de paso, en un sistema jurídico de corte acusatorio, el juez está obligado a indicarles a las partes las razones en las que sustentó su sentencia, es decir, cuáles fueron los criterios que lo llevaron a tomar una decisión. A manera de ejemplo, el juez señalará cuál litigante demostró sus planteamientos y expondrá los argumentos fácticos y jurídicos que sustentan su decisión. En otras palabras, para fundamentar una resolución, es indispensable que esta se justifique racionalmente y que sea la conclusión de una inferencia o sucesivas inferencias formalmente correctas, y que sea también producto del respeto a los principios y a las reglas lógicas. Ahora bien, detrás de este proceso decisorio se ubican y se infiltran predisposiciones temperamentales, sentimientos de justicia e incluso el instinto. Pocas veces se hace referencia a ellos pero la toma de decisiones de todos los seres humanos involucra estos sesgos cognitivos. Es así que la deliberación del juez está impregnada de prejuicios, estereotipos e ideologías las cuales resultan inseparables en su determinación. Para algunos autores como MuÑOZ ArAnguren -quien retoma el trabajo de TVERSKY y KAHNEMAN y lo aplica a las decisiones judiciales-, los errores y sesgos en que incurre el ser humano se producen en forma inevitable al utilizar la mente para procesar la información que recibe del exterior (Muñoz Aranguren, 2011, p. 3).

Conviene señalar en este momento que por sesgos se entienden aquellas reglas cognitivas que, inconscientemente, todo ser humano aplica al procesar la información que recibe del exterior, y que permiten "reducir las tareas complejas de asignar probabilidad y predecir valores a operaciones de juicio más simples" (ídem). También son llamados procedimientos heurísticos por tratarse de procedimientos mentales que todos los seres humanos llevamos a cabo cuando percibimos y analizamos una determinada situación. Pues bien, estos procesos mentales no son ajenos a la labor jurisdiccional derivada de una controversia o procedimiento legal. En efecto, llegan a ser más latentes en los sistemas de enjuiciamiento de corte acusatorio que, entre otros, se rigen por el principio de inmediación, el cual hace necesaria y obligada la presencia de las partes y del órgano jurisdiccional para valorar directamente las pruebas. Desde esta perspectiva, el órgano resolutor -que tiene contacto inmediato con las partes y con las personas que constituyen la fuente de la prueba-, valora las miradas, los gestos, las actitudes, el nerviosismo y las reacciones de cuantos intervienen en las audiencias.

En este sentido, el órgano de valoración de la prueba tendrá en cuenta la expresión verbal y corporal del deponente y las considerará al evaluar la credibilidad que se le confiera a su dicho. Todo lo anterior le permite fundar su convicción acerca de la veracidad o deshonestidad de las respectivas declaraciones. Además de ello, facto- 
res como el género del justiciable, su clase social, la pertenencia a un determinado grupo racial o minoría étnica influyen en la toma de decisiones del juez, no obstante esto pueda ser inadvertido por el mismo órgano decisor. El conocimiento general del mundo y las experiencias adquiridas durante la propia existencia denotan significado para que el juez adquiera certeza sobre la ocurrencia o no ocurrencia del hecho (ídem).

Ahora bien, en el sistema de justicia penal de corte acusatorio la norma misma dispone que el juez valorará la causa de acuerdo al sentido común y a la lógica, dejando la puerta abierta a que estos sesgos converjan en la actividad mental que despliega el funcionario judicial. Sin embargo, la intención de este trabajo es promover que los tribunales resuelvan conforme a criterios no meramente intuitivos. Asimismo, creemos pertinente que estos fenómenos sean reconocidos para sentar las bases de nuevos estudios, de tal forma que se puedan menguar las resoluciones judiciales basadas en intuiciones subjetivas, sentimientos o en ideas preconcebidas, ya que ellas dan por consecuencia que las resoluciones judiciales carezcan de certeza y previsibilidad.

\subsection{La psicología y la decisión judicial}

En el caso concreto de la decisión judicial y desde la perspectiva de las ciencias sociales y humanas, es imprescindible el estudio de los procesos cognitivos -biopsicosociales- que concurren en una decisión. En efecto, en la búsqueda de un sistema judicial más transparente y confiable, es necesario atender estos aspectos ya que, como apunta SORIA, "una decisión judicial es un acto que afecta al propio sistema penal, pero también en grado variable a la sociedad en general, al agresor, a la víctima y al sistema penitenciario" (SORIA Verde y SÁIz RoCA, 2006, p 190). Coincidimos con este autor en que, a fin de cuentas, quien juzga carga con todo un cúmulo empírico biopsicosocial del que es imposible desprenderse al momento de ejercer la alta labor de juzgar.

El desconocimiento que se tiene con respecto a estos procesos es considerable, sin embargo, diversos autores advierten la necesaria inclusión de la psicología en las labores jurídicas, máxime que siempre han existido sesgos cognitivos en los actores jurídicos, como comentan SABATÉ, BAYÉS y Munné, quienes citan a Frank Jerome, “”... todos sabemos que las condiciones físicas o mentales de los jueces tienen un marcado efecto en sus resoluciones" (MuÑoz SABATÉ y Munné, 2008, p. 63). En palabras de OvEJERo (2009), podemos aclarar la participación del psicólogo de la siguiente manera: "Para entender bien los mecanismos implícitos en la formación de juicios, así como para que puedan adoptar estrategias de afrontamiento de estos riesgos y, por tanto, para que no caigan como víctimas ingenuas en los sesgos y errores que les esperan como auténticas trampas escondidas en su mismo interior" (OvEJERO BERNAL, p. 218).

Si bien es cierto, los aportes y alcances de la Psicología y la Psicología Jurídica no se limitan únicamente al Derecho Penal, su bagaje epistemológico puede comprender una gran cantidad de directrices “de, en y para” el derecho. De acuerdo con SABATÉ, 
MunNÉ y BAYÉS, dicha influencia se incrementa en el procedimiento penal acusatorio ya que, si bien la metodología de los juicios orales es benéfica y propicia de un ambiente de impartición de justicia más transparente, en el que el juez se involucra y está cerca del justiciable, también se ve expuesto a una mayor cantidad de influjos de los que puede tener consciencia o no y que a la postre, pueden ser definitorios al momento de tomar una decisión (MuÑOZ SABATÉ et al., ob cit., pp. 52-53).

Muchos de los estímulos que son expuestos en un juicio son en realidad ajenos o, bien, lejanos al bagaje epistémico y entender del derecho y, en efecto, la investidura del juez indica que es una persona docta en leyes, jurisprudencia, dogmática y filosofía del derecho, sin embargo, escapa a una gran gama de técnicas, metodologías, epistemologías y lenguajes utilizados por otras ciencias que sí utiliza a fin de emitir su juicio. Es así que cualquier estímulo visual o auditivo -como la apariencia de la víctima o del acusado, las emociones, las conductas, la manera y emotividad con la que los participantes se expresan entre muchas otras cosas- pueden despertar o activar en el juzgador respuestas relacionadas con prejuicios, estereotipos, carencias o situaciones subconscientes de las que el funcionario judicial no tiene conocimiento y que pueden parcializar la decisión final a favor o en contra de algún participante.

Como comenta REIK, a propósito de las actividades de la psicología forense -citado en SABATÉ, MunnÉ y BAYÉS-, "se ha dudado y con razón de la comprensión y conocimiento de los jueces para resolver esta clase de problemas [psicológicos]. Es como tratar de llegar a las capas más profundas de la tierra con una pala de juguete" (REIK, 1965, p. 55).

Debe entenderse que las variables que pueden llegar a despertar en el juez reacciones conscientes así como subconscientes ${ }^{8}$ son multi e interfactoriales y abarcan todo tipo de influencias a las que el juzgador ha estado y se encuentra expuesto y sin que existan límites definidos sobre dónde termina una y comienza la otra. Así, desde una perspectiva intrínseca, se mencionan la infancia, estilo de crianza, acontecimientos traumáticos, juicios y prejuicios familiares, valores, motivaciones, sistema de creencias, etapas madurativas, entre otros. Entre los factores extrínsecos se encuentran lo económico, lo político, lo social, lo colectivo y hasta lo religioso, aspectos que se suman al conocimiento jurídico que posee quien juzga. Es así que tanto en el ámbito jurídico como en el psicológico existen variables dependientes e independientes y de acuerdo con la normativa o el nivel de profesionalización de las actividades, se atiende a estas de la manera más concreta posible. Sin embargo, surgen en ambos campos las variables extrañas, y mientras estas se estudian en laboratorios de psicología, en los tribunales son desconocidas.

8 Se evita el uso del término "inconsciente" debido a que es un constructo proveniente del psicoanálisis. 
SORIA, por su parte, comenta que "existen dos grandes grupos de factores que afectan la toma de decisiones de jueces y tribunales; los legales, compuestos por la ley, la jurisprudencia y el procedimiento y, en segundo término, los extralegales" (MUÑOZ SABATÉ et al., ob. cit., p. 63). La categoría relacionada con lo legal ciertamente se relaciona con las normas que la propia dogmática del derecho crea, fundamenta y promueve; todas las conductas prohibidas y sancionadas por los códigos, así como la consideración de sus respectivas penas. Sin embargo, y a decir de Soria, es la interpretación personal y profesional del juez de la misma [la ley] la que definirá el resultado final, por ello siempre debemos tomar en cuenta otros elementos extrajudiciales (SORIA Verde y SÁIz RocA, 2006, p. 190). Se pueden mencionar, por ejemplo, los fenómenos colectivos y el termómetro social que en ese momento se suscitan, la presión social, las políticas públicas y las reformas legales redactadas en el propio país o bien derivadas de tratados internacionales, sugieren en el juzgador una inclinación obligada.

Además, de acuerdo a la naturaleza del proceso, el juez se encuentra orientado a dirigir el asunto de una manera metódica, cumpliendo con cierta temporalidad y en algunas ocasiones estas características pueden llegar a apresurar o no profundizar un caso, sin considerar de manera correcta todas las variables. Siguiendo a SorIA, "entre los factores extralegales, tres han sido señalados como los más importantes: el contexto judicial de la decisión, la personalidad del juez y las características del juez" (ídem). A continuación, se ahonda en cada uno de ellos.

El contexto judicial de la decisión parte de dos principios. El primero, referente a la instancia procesal en que se encuentre el caso y a la función encomendada a cada operador. Así, policía investigadora, ministerios públicos, jueces de control o de juicio oral llevan a cabo diversas actividades y en diferentes momentos, siendo que mediante sesgos o influjos pueden aprobar o desechar evidencia que pudo ser de relevancia para otro personaje en otro momento en el proceso. Ligado a lo anterior, se encuentra el segundo principio, que consta de las "interdecisiones" que se van acumulando durante el proceso, ya que la sentencia final es la sumatoria de todas las decisiones previas realizadas por todos los actores jurídicos intervinientes en el caso particular.

Relacionado a los factores de contexto y como ya se hizo patente en párrafos anteriores, destacan las opiniones profesionales, las pruebas periciales, la influencia social de la decisión, el contexto social, el tipo de proceso decisor, la tendencia del juzgador y la interpretación personal de la ley y la jurisprudencia, de acuerdo con SORIA (ídem). En relación con la influencia y el contexto social, el juez debe ser muy cuidadoso, ya que cada decisión que toma genera un criterio que puede crear una percepción positiva o negativa en la colectividad. Es común que el juez guarde prudencia cuando se tratan temas controversiales o en los cuales la comunidad se encuentra sensibilizada. Actualmente, por ejemplo, temas sobre discriminación y violencia doméstica o policial influyen en la sociedad, la cual genera presiones para 
decantar las decisiones hacia un lado u otro, en donde, si bien la ley expresa una forma, debido a la necesidad de la contención político-social del microgrupo o grupos, la decisión se carga hacia la parcialidad más activa política o socialmente, recordando que la principal función de la ley es mantener el equilibrio de la generalidad.

De hecho, de acuerdo con RodríGUEZ MANZANERA (2010), es necesario traer a colación que esencialmente las leyes son reflejo de los deseos y tradiciones que evolucionan junto con la sociedad, ya que "son el reflejo fiel del sentir y querer sociales". Nuestra realidad es diferente en el sentido de que no solo existe ya un grupo dominante que trata de normativizar a una masa minoritaria; en la actualidad, existen múltiples microgrupos pugnando por lo que ellos consideran sus "derechos" y, en ocasiones, algunos de estos ejercen presión político-social para lograrlos. Es deber de quien decide tratar de mediar dichas pugnas para lograr la sentencia más apegada con la justicia; de lo contrario, solo se estará apoyando la tesis de que se es posible obtener beneficios de manera más fácil por medio de la coercibilidad. Por otro lado, las redes sociales y las Tecnologías de la Información y la Comunicación (TIC) pueden jugar un papel sobresaliente debido a la publicidad del proceso penal acusatorio. Estos medios pueden ser utilizados para ejercer presión social a los tribunales a efecto de lograr una absolución o una condena, y el Juez deberá estar preparado para hacer frente a estas disposiciones a fin de que su trabajo pueda estar libre de reticencias.

Finalmente, la personalidad y las características del Juez se relacionan con la parte más íntima y más profunda del juzgador y se compone de todas aquellas experiencias, pensamientos, valores, actitudes, sistemas de creencias y acciones que lo condujeron a ser la persona que es. No olvidemos que, a fin de cuentas, cuando termina sus labores, en el momento en que el juez se retira la toga, solo queda un individuo más, con afectos, carencias, angustias, pensamientos propios y una vasta lista de características personales. Es mediante este sistema de creencias que el juez puede involucrar conflictos y experiencias personales cuando juzga un caso, y puede caer en el error de empatizar o bien demeritar las actitudes de las partes en litigio, suponer características simplemente de la recolección de información sensorial, o despertar en él juicios de valor con relación a ciertas características como edad, juicios o sentencias previas, tipo de delito cometido, entre otros. En relación con la toma de decisiones, Soria ha manifestado que la característica más importante de este aspecto está relacionada con la ideología, las actitudes hacia el caso juzgado y la implicación emocional en los hechos (SORIA VERdE y SÁIz RocA, 2010, p. 192).

Pues bien, teniendo en cuenta los conceptos que anteceden, es preciso señalar que en todos los casos el órgano jurisdiccional está llamado a hacer un análisis crítico de la prueba que sustenta el caso. La valoración de la misma se realiza respecto de valores intersubjetivos, es decir, que pueden ser apreciados por más de un sujeto no siendo aceptable que el juez decida exclusivamente sobre la base intuitiva e irreflexiva de sus emociones individuales. De hecho, se exige al juez que base su fallo en apreciaciones fácticas y jurídicas, y que funde y motive su resolución, aspectos 
que además de hacer jurídicamente aceptable la decisión, representan una garantía de seguridad para la ciudadanía.

Se ha apuntado, sin embargo, que en la elaboración de las sentencias, la intuición y el sentimiento tienen una participación más significativa de lo que a primera vista se puede advertir y, como bien refiere CALAMANDREI (2009, p. 120), "no por nada -diría alguno-, sentencia deriva de sentir". En este sentido, es indudable que siendo la justicia un sentimiento humano racionalizado predominen los cánones del instinto sobre el derecho escrito. A partir de las ideas expuestas, se anota que el juez siente por intuición de qué parte está la razón. Es por ello que el mencionado autor señala que "muchas veces los motivos que se declaran distan mucho de ser los verdaderos; y que muy a menudo la motivación oficial es una pantalla dialéctica para ocultar los verdaderos móviles, de carácter sentimental o político, que han llevado al juez a juzgar como lo ha hecho" (ídem). Algunas veces, consiguen demostrar con argumentos una congruencia entre su sentencia y su motivación, la cual no comprometa su opinión e intuición personal de la cuestión de derecho.

En este tenor, el juez siente de qué parte está la razón y, en su labor, busca los argumentos lógicos idóneos para demostrar los pormenores de su resolución. Apreciamos, coincidiendo con Calamandrei, que la dificultad de juzgar no consiste tanto en encontrar la conclusión que encierra su fallo, sino que más complejo resulta reflexionar y encontrar las premisas en que se apoya su conclusión, muchas veces sugerida por el sentimiento (ídem, pp. 121-129). De ahí que las premisas o argumentos lógicos aparezcan después de la conclusión a la que arriba el juez.

Este fenómeno del comportamiento ha sido estudiado por las áreas del pensamiento, que incluso han dispuesto que existen disfunciones cognitivas en todo ser humano, y que estas disfunciones se dan en todos los países y culturas y sería una presunción extremadamente atrevida pretender que los jueces y jurados se hallan indemnes a la influencia de estos llamados errores cognitivos (MuÑoz ARANGUREN, 2012, p. 65). De lo anterior se deduce que, en efecto, existe el riesgo de que la certeza objetiva que el juzgador ha adquirido sobre la culpabilidad de un individuo se vea fuertemente cuestionada por fenómenos subconscientes presentes en la mente del resolutor.

Se aprecia, entonces, que, en la elaboración de su resolución, el órgano de valoración puede fácilmente quedar expuesto a errores cognitivos y como se ha expuesto, factores extralegales como la edad, el género, si se trata de un juez severo o menos severo o si se inclina a favorecer las pretensiones de la Fiscalía, inevitablemente se proyectan en la toma de la decisión judicial, sin que refleje esta una aplicación rigurosa de la ley. De ello se deriva que existan sentencias diversas de casos idénticos.

POSNER hace una reflexión al analizar la sustitución de un juez, reemplazado por otro que a su parecer posee una esencia de pensamiento diferente, así como sus repercusiones en materia jurisdiccional. Comenta que 
Este giro resulta de la sustitución de un juez moderadamente conservador (O'CONNOR) por otro extremadamente conservador (ALITO), cambio que ha traído a un primer plano la pregunta acerca de cómo los elementos personales y políticos pueden influir en la actividad de juzgar y, con ello, el sentido en que el país esté siendo gobernado por los jueces en lugar de por las leyes. Si un cambio en los jueces trae aparejado un cambio en el derecho... (PosNer, 2008, p. 12).

Su análisis lo lleva a aceptar que "los jueces no son ni gigantes morales o intelectuales (qué se le va a hacer), ni profetas, oráculos ni meros portavoces o máquinas calculadoras. Son trabajadores 'humanos, demasiado humanos' que reaccionan del mismo modo que lo hacen otros trabajadores ante las condiciones del mercado de trabajo en el que actúan" (ídem, p. 18). Entonces, queda claro que tanto las proyecciones como las concepciones ideológicas y los valores en que se fundamenta la concepción que el juez tiene del mundo serán un sesgo de anclaje en su determinación. Por lo tanto, los sesgos cognitivos no son algo ajeno al mundo del Derecho. Esto da pauta a que, de no ser conscientes los resolutores de esta realidad, la sociedad quede frente a una justicia unas veces clasista, sexista, selectiva, y otras tantas, xenófoba.

\section{SUBJETIVIDAD Y ACTITUDES DEL JUEZ}

Consideramos que generalizar o estigmatizar no es la manera más efectiva de darle solución a este fenómeno. Lo que proponemos en este punto es identificar, estudiar y rectificar atitudes en el que juzga; tareas pertenecientes al área de la Psicología Jurídica. Con propósitos de categorizar las diversas conductas que tiene el juez, se presentan algunas clasificaciones que se han realizado en este respecto.

Piero CalamandRei reconoce y separa al juez lógico y al juez sensible del juez consecuente y el juez precursor. GüIDI, por su parte, en un trabajo científico y relatando sentencias en delitos tan importantes como la violación y el maltrato de la mujer, aparecidas en los periódicos de mayor circulación, realiza un esfuerzo por clasificar las actitudes y conductas del juez en seis categorías, siendo estas el juez machista, el juez redentor, el juez estrella, el juez político, el juez genético y el juez elitista (GÜIDI CLAS, 2003, pp. 339-350), que se analizan a continuación. La autora analiza los motivos que conllevan a una actitud machista o discriminatoria, para lo cual se auxilia de la psiquiatría, entre otros estudios, determinando si algunos trastornos de la personalidad pueden ser o no compatibles con la función judicial.

En cuanto al juez machista, la autora hace referencia a las actitudes operacionales que tienen algunos jueces al promover sentencias en donde el análisis refleja un marcado machismo, acentuado por las referencias que estos hacen denotando lo que ella interpreta como "la inferioridad de sexo o ciertos descalificativos por el hecho de ser mujer".Así, estas conjeturas pueden brotar de tres situaciones particulares: a) 
que se ponga de manifiesto un odio irracional contra la mujer; $b$ ) que se considere a la mujer como un sexo inferior y, por consecuencia, superior el del hombre, y c) que dicha actitud obedezca a una represión sexual, donde resalta el papel que juega la madre del juez en relación al entendimiento de este actor jurídico con las demás féminas. Comenta además que estos jueces del tipo macho tienen una visión de la mujer que no se ajusta a los tiempos actuales.

$\mathrm{El}$ juez redentor posee "una paranoia con delirio místico o incluso una esquizofrenia dominada por dicho delirio". Los integrantes de este grupo son poseedores de una creencia irracional de ser los elegidos para salvaguardar a la humanidad, inmiscuyéndose en situaciones en las que poco tienen de práctica. Acusan a sus detractores de corruptos y presentan una tipología de personalidad con rasgos malhumorados, agresivos, estresados y vengativos (ídem, p. 341).

El juez estrella se caracteriza por ser una persona que anhela la atención pública, que goza de las miradas hacia su persona y que sacrificará cualquier cosa por seguir manteniendo su estatus del "mejor juez". Gusta de que lo vean en cartelera, que los periódicos hablen de él y que la comunidad piense que es el único que trabaja y que sin él, el país quedaría en un estado de indefensión. Sus rasgos distintivos son del "tipo ciclotímico, pícnico y viscerotónico [...] personalidad mixta que comprende trastornos narcisista e histriónico" (ídem, p. 341).

El juez político es un militante más de su partido político y un deudor eterno de quien lo colocó en esa posición. Defiende a toda a costa sus intereses, los de sus conocidos y los de su partido, a fin de que en un futuro estos lo reconozcan ofreciéndole mayores beneficios que conllevan la característica del manejo del poder. Sus características son del tipo mixto, con raíces narcisista, histriónica y agresiva, manipulador y explotador de los demás (ídem, p. 345).

De acuerdo con GüIDI, el juez genético incluye a los jueces que son tales debido a abolengo, a casta, ya que sus antepasados se desempeñaron de igual manera en la carrera judicial. Principalmente orillados a esta labor por sus padres o por el nombre de la familia, lo que demuestra un rasgo de personalidad sumiso-negativista y con características depresivas (ídem, p. 348). Este tipo de jueces ven su labor como una pesada carga a la que no le pondrán el más mínimo esfuerzo, retrasando resoluciones, asintiendo en cualquier discusión, carentes de interés para revisar las periciales, siendo quizás los que más prevarican durante su cargo.

El juez elitista es definido como el personaje que proveniente de una familia de pocos recursos, que queda deslumbrado al reconocer la cantidad de lujos y beneficios a los que se accede cuando se llega a un puesto tan importante como el de juez o magistrado. Forman su carácter "la paranoia con delirio de grandeza o delirio de poder" o "un trastorno de personalidad mixta: narcisista agresiva histriónica”. Estos 
rasgos lo llevarían a desconfiar de todas las personas por la suposición de que pueden arrebatarle lo que posee, así como agresividad para defenderlo (ídem, p. 350).

Habiendo hecho referencia a la clasificación anterior, consideramos que aunque es una aproximación que enmarca las disposiciones y tendencias de los sujetos, específicamente, los actores judiciales, la crítica es en el sentido de que etiqueta a los jueces retomando constructos psicológicos y psiquiátricos que dejaron de utilizarse desde hace largo tiempo y se aplican para generalizar sin la posesión de un conocimiento más profundo respecto de lo que se trata de explicar. Esta ordenación plantea señalamientos negativos en todos los casos, y apunta a que estas conductas se deben a situaciones motivadas por trastornos de la personalidad matizados de ideas paranoicas, esquizofrénicas, de 'neurosis obsesiva' o bien, sumiso-dependientes. Reconocemos que no se puede deducir que en todos los casos las disposiciones de conducta del juez obedecen a estos fenómenos. Debemos entender, pues, que una actitud, creencia, valor o motivo erróneos no necesariamente se relacionan con 'enfermedad', sino que son producto del bagaje psicosocial en el que las personas se encontraron inmersas desde temprana edad y hasta la actualidad; añadimos que todas las personas pueden caer en algún momento en dichas diferencias de pensamiento, no significando necesariamente que estén locas o enfermas.

Por otro lado, esta clasificación no se fundamenta en estudios propiamente conductuales y no contempla tipos de predisposiciones judiciales no necesariamente negativas. Apreciamos que deja fuera los temperamentos del juzgador y las emociones dominantes en cada tipo. Por último, no presenta ningún tipo de relación con los modelos de personalidad sanguínea, colérica, flemática o melancólica, propuestos desde HiPÓCRATES y que reflejan las conductas afectivas y las reacciones emocionales (SCHMIDT et al., 2010). Lo realmente peligroso de este ejercicio es llegar a generalizar o marcar perniciosamente a los jueces; no se trata de emitir un juicio negativo sobre el funcionario judicial, máxime que esta postura, en lugar de contribuir en la resolución de la problemática, solo alimentaría la desconfianza social en la labor judicial.

Con la intención de ilustrar algunas de las tendencias del juez mexicano, podemos repasar los casos de homicidios por razones de género. Las investigaciones arrojan que las agresiones y homicidios derivados de su condición de mujeres en México se han disparado un 155\% entre 2007 y 2012. Según el Instituto Nacional de Estadística y Geografía (INEGI) se registraron 2.764 casos, y según cifras del Observatorio Nacional contra el Feminicidio, una organización privada, se calcula que entre 2012 y 2013 cerca de 3.892 mujeres fueron asesinadas en todo México. Aunado a lo anterior, se estima que en el país, en el año 2012, la tasa de homicidios de mujeres fue de 4,6 muertes por cada $100 \mathrm{mil}^{9}$. En estos casos, el papel del juez es preponderante

9 Estadísticas del feminicidio en México - Versión ejecutiva, Centro de Estudios para el Adelanto de las Mujeres y la Equidad de Género, febrero 2014. 
pues es él quien deberá considerar que el homicidio se cometió por razones de género para seguir el proceso por feminicidio y es él quien determina si se cometió este crimen o no.

En estos casos, situaciones tales como el entorno en que se ha desarrollado el juez, la incidencia de este tipo de delitos en la entidad federativa en la que vive o bien el mismo entorno familiar, influirá en la determinación que tome el juzgador. Como se ha mencionado a lo largo de este artículo, la inclinación que tenga el juez al dictar su sentencia obecede en cierta medida a las reacciones emocionales y los estilos cogntivos de los funcionarios que dictan las resoluciones.

Otro caso es el de las minorías indígenas en el país. No son pocas las ocasiones en que han perdido sus tierras frente a grandes proyectos de construcción. En otros casos que apuntamos a continuación, después de los fallos pronunciados por los tribunales mexicanos, la Corte Interamericana de Derechos Humanos ha dispuesto que el gobierno mexicano indemnice a indígenas por violaciones a los derechos a la libertad e integridad personales, así como a las garantías judiciales. En el caso de Juan García Cruz, indígena nahua de Puebla, y Santiago Sánchez Silvestre, de origen mixteco, de Oaxaca, fueron acusados de formar parte del Ejército Popular Revolucionario (EPR), de repartir propaganda en el metro y de portar armas, además de haber participado en el homicidio de un policía del Estado de México. A pesar de que sus declaraciones fueron obtenidas por medio de tortura, fueron sentenciados en primera instancia el 28 de agosto de 1998. El juzgado los declaró penalmente responsables de la comisión del delito de 'portación de arma de fuego de uso exclusivo del Ejército, Armada y Fuerza Aérea’, condenándolos a tres años de prisión y multa de doce días". El 6 de septiembre de 2001, el juez de primera instancia dictó la sentencia estableciendo su responsabilidad penal. La interposición de un recurso de apelación contra esta sentencia se resolvió confirmando la condena ${ }^{10}$.

Otro caso fue el de Teodoro Cabrera García y Rodolfo Montiel Flores, de la Sierra de Petatlán y Coyuca de Catalá. Ellos fueron denunciados por el Ejército por portación de armas de fuego de uso exclusivo de las Fuerzas Armadas y por siembra de amapola y marihuana. Alegaron tortura, incomunicación y detención ilegal; sin embargo, el 28 de agosto de 2000, el Juez Quinto de Distrito del Vigésimo Primer Circuito en Coyuca de Catalán dictó sentencia mediante la cual condenó a pena privativa de libertad de 6 años y de 8 meses a CABRERA GARCía y condenó a 10 años de prisión al señor MONTIEL FLORES. La sentencia fue confirmada en segunda instancia ${ }^{11}$.

10 Ficha técnica: García Cruz y Sánchez Silvestre vs. Estados Unidos Mexicanos. http://www.corteidh. or.cr/cf/Jurisprudencia/ficha.cfm?nId_Ficha=378\&lang=es.

11 Demanda ante la Corte Interamericana de Derechos Humanos en el caso de Teodoro Cabrera García y Rodolfo Montiel Flores (caso 12.449) contra los Estados Unidos Mexicanos, Comisión Interamericana de Derechos Humanos, 2009. Disponible en: http://www.cidh.org/demandas/12.449\%20Teodoro\%20 Cabrera\%20Garcia\%20y\%20Rodolfo\%20Montiel\%20Flores\%20Mexico\%2024jun09\%20ESP.pdf. 
En noviembre de 2010, la Corte Interamericana de Derechos Humanos declaró, por unanimidad, que el Estado de México resultó internacionalmente responsable por la violación de los derechos a la libertad personal, integridad personal, garantías judiciales y protección judicial en perjuicio de los señores Cabrera García y Montiel Flores.

Un caso más es el de Alberto Patishtán, profesor tzotzil originario de la comunidad El Bosque, en Chiapas, quien fue detenido en junio de 2000 acusado de participar en una emboscada donde murieron siete policías. El primer juez responsable del caso desechó testimonios que ubicaron al profesor en otro sitio cuando ocurrió el ataque y solo tomó en cuenta el informe de la PGR y el argumento del testigo principal. El 18 de marzo de 2002, el maestro fue condenado a 60 años de prisión por delitos de lesiones, homicidio calificado, robo calificado, daños y portación de armas de fuego de uso exclusivo del ejército mexicano. La sentencia fue ratificada por el juez encargado de la apelación y por un tribunal colegiado.

Ante estos escenarios, la Comisión Nacional de Derechos Humanos (CNDH) ha destacado que miembros de cien grupos étnicos entre los que destacaban los náhuatl, tzeltal, tzotzil, zapotecos y mixtecos han sido condenados por homicidio, violencia familiar, violación y secuestro firmando sentencia sin un intérprete y sin entender ni hablar el español. Estos casos ponen de manifiesto que pertenecer a una comunidad indígena supone una condena en muchísimos $\operatorname{casos}^{12}$. Tomar en cuenta las cifras que manejan ONG y otras instituciones refleja un panorama que evidencia la necesidad de un cambio en estas tendencias, para así hacer realidad el concepto de que todos los seres humanos son iguales ante la ley. Reconocer la existencia de estos sesgos abonaría la garantía que tenemos los ciudadanos a un juez imparcial y a un juicio justo, y renovaría la confianza del gobernado en el sistema acusatorio.

En otro ángulo de este estudio y de acuerdo con los diversos tipos de sesgos cognitivos a que es propenso el ser humano según MuÑoz ARANGUREN, hemos tomado aquellos que tienen mayor incidencia en la labor judicial:

\section{SESGOS COGNITIVOS PRESENTES EN LA LABOR JUDICIAL}

\subsection{Sesgo retrospectivo}

Resulta extraordinariamente difícil realizar juicios sobre lo acontencido abstrayéndose por completo del resultado. Según este sesgo, el individuo no puede abstraerse de las consecuencias de los hechos que juzga por lo que a un juzgador le parece in-

12 De acuerdo con la Comisión Nacional de Derechos Humanos (CNDH), en el país hay más de 8.500 indígenas que permanecen en prisión. Disponible en http://www.milenio.com/politica/procesoindigenas-recluidos-carcel-defensa-justicia-Mexico-derechos_humanos-CNDH_0_347365280.html. 
evitable el resultado. Como ejemplo, el conocimiento de lo ocurrido, que puede ser el resultado dañino o lesivo, condiciona el resultado, concluyendo por ejemplo que este se ejecutó descuidadamente (Muñoz Aranguren, Ob. cit., p. 6).

\subsection{Sesgo de la representatividad}

Este proceso mental alude al mecanismo de 'valoración', del cual hacen uso los juzgadores para discernir entre la etiqueta colocada al sujeto ya sea víctima o acusado y sus actitudes en el tribunal. De acuerdo con este proceso, las personas se comportan según su categorización. Si, por ejemplo, un acusado se comporta de manera angustiada o nerviosa en el estrado y responde en forma poco ortodoxa a las preguntas hechas por el fiscal, a ojos de un juez, estas actitudes pueden ser un indicio suficiente para considerarlo culpable. Por el contrario, cuando el comportamiento observado de la persona en estrado no se ajusta a lo esperado por el juzgador, se asume lo contrario. Para ilustrar, cuando quien se señala como acusado actúa de manera tranquila, el juzgador supondrá que es inocente (ídem, pp. 3 y 4).

Ahora bien, en el nuevo sistema de justicia penal, el principio de inmediación es un principio rector mediante el cual se asegura que quien juzga pueda conocer directamente y escuche de viva voz a los implicados del asunto. Sin embargo, este contacto o aproximación trae consigo nuevos retos para quien imparte justicia, ya que de acuerdo a GuTHRIE et al., citado por MUÑOZ ARANGUREN, el sesgo o procedimiento heurístico de la representatividad y con él las representaciones erróneas que pueda llegar a tener el tribunal, se yergue como uno de los principales obstáculos de la impartición de justicia (ídem).

No obstante lo anterior, es importante señalar que aunque es un prejuicio muy arraigado en la sociedad, el tener una actitud nerviosa o tranquila en el momento de emitir la declaración en un tribunal no tiene nada que ver con ser inocente o culpable. Como seres humanos, reaccionamos de diferente manera a los estímulos ambientales, por lo que es posible que las personas -incluidos además policías, ministerios públicos, testigos, peritos-implicadas en un proceso judicial reaccionen de muy diversas maneras en el estrado. En este escenario, un imputado puede reaccionar de manera nerviosa no porque se sepa culpable, sino porque entiende que su libertad está en juego.

\subsection{Sesgo de confirmación}

Este proceso mental se caracteriza por la tendencia del sujeto a filtrar una información que recibe, de manera que, de forma inconsciente, busca y sobrevalora las pruebas y argumentos que confirman su propia posición inicial al mismo tiempo que ignora y no valora las pruebas y argumentos que no respaldan la misma (ídem, pp. 8 y 9). 
Desde la perspectiva de MERTON, el sesgo de confirmación es una tendencia irracional a buscar, interpretar o recordar información de una manera tal que confirme alguna de nuestras concepciones iniciales o hipótesis. Es un tipo de sesgo cognitivo, es decir, un error sistemático del razonamiento inductivo. Según este autor, estos sesgos en el procesamiento de la información son diferentes a los efectos de confirmación de comportamiento (lo que se conoce como profecía autocumplida), en los que las expectativas de una persona influyen en su propia conducta (MERTON, 1968).

Desde esta perspectiva, un juez que ha formulado previamente una conclusión respecto de una persona y su caso particular mediante el gran número de procesos mentales que hemos comentado anteriormente, se encontrará en mayor disposición de hacer caso a hechos y comentarios que afirmen su tesis inicial, ignorando o desvalorizando aquellas tesis que la desvirtúan.

\subsection{Sesgo de grupo}

Esta técnica cognitiva provoca el error de valorar de forma injustificadamente homogénea las actitudes, actos y opiniones de las personas que pertenecen al mismo grupo, y por la sola razón de pertenencia a ese grupo. Esos prejuicios pueden ser tanto positivos como negativos, y pueden darse por la pertenencia o no del propio sujeto a uno de esos grupos (ídem).

De esta manera, el juez puede categorizar como un mejor trabajo pruebas más convincentes o argumentos más sólidos que aquellos emitidos por la fiscalía, ya que, de hecho, pertenecen a la misma institución que es el Estado.

En este sentido, se ha tratado de dejar de lado, al menos desde un punto de vista institucional, "la prueba tasada" y se argumenta que en este nuevo modelo el juez valorará con las máximas de la experiencia y mediante la sana crítica las pruebas desahogadas. Sin embargo, existe una "tasación" desde el mismo instante en que unas pruebas son ofrecidas por el Estado y otra cuando son ofrecidas por litigantes externos, de los cuales se puede presuponer falta de cientificidad, de técnica, de preparación, entre otras circunstancias.

\subsection{Sesgo de disponibilidad}

De acuerdo con el procedimiento mental denominado heurístico de disponibilidad, el sujeto procede a valorar la probabilidad de que acaezca un suceso, tomando en consideración la facilidad con la que el propio sujeto puede recordar o imaginar ejemplos de sucesos similares (ídem). 
Bajo este precepto y aplicándolo al ámbito jurisdiccional, las decisiones judiciales estarán influenciadas por casos previos que tengan algún parecido con el actual. Específicamente, se sobreestima la información recabada en el pasado y, por tanto, se formulan conclusiones erróneas. A manera de ejemplo, si un juez decidió previamente en dos casos que el acusado cometió un homicidio, existe mayor probabilidad de que en un caso similar condene al procesado.

\subsection{Sesgo de anclaje y ajuste}

Este proceso mental se fundamenta en la realización de una estimación, por parte del sujeto, a partir de un valor inicial -conocida como anclaje-, que progresivamente ajusta a medida que va obteniendo información adicional. Los múltiples estudios realizados acreditan cómo este procedimiento mental da lugar a resultados diferentes, simplemente por el hecho de que se haya empezado por un valor distinto. De lo anterior se deriva que, con frecuencia, la valoración inicial ejerce una influencia indebida y desproporcionada sobre el análisis del sujeto, y provoca errores que pasan inadvertidos para el propio interesado (ídem).

Este procedimiento de pensamiento ocurre en mayor medida en las decisiones del jurado, ya que este aplica principalmente a grupos. Alude a la tendencia que existe de adecuar la decisión de acuerdo con la opinión o sentencia más severa. Por lo tanto, si en un jurado una persona propone aplicar la máxima pena a un imputado, los demás sentenciarán una condena menor pero inclinada siempre hacia la pena mayor.

Hasta aquí hemos podido observar el poder que ejercen diversos influjos en la determinación del fallo del juez, y que este no es producto únicamente de una determinada interpretación y aplicación del Derecho. Es desde esta perspectiva que el campo de la psicología puede contribuir copiosamente, haciendo disponible y accesible el conocimiento que ha conquistado sobre los procesos cognitivos humanos. Además, es importante anotar que si bien no existen demasiados antecedentes con relación al estudio de estos fenómenos en México, el hecho de que todo esto no se haya estudiado no significa que no exista ni que carezca de importancia.

\section{CONCLUSIONES}

Las principales conclusiones a las que hemos arribado son:

- El procedimiento penal acusatorio mexicano, específicamente, el Código Nacional de Procedimientos Penales, enmarca un sistema de valoración judicial que en gran medida otorga un considerable margen de libertad al juez siendo que sus criterios de discernimiento obedecen, más que a la norma jurídica, a normas de su lógica, de su sentido común y de su experiencia. De la lectura de la ley adjetiva penal en 
comento se advierte que en el ejercicio de tomar una posición u obtener un juicio con respecto a las pruebas a desahogar, estas deben ser observadas bajo el principio de la "sana crítica". En dicho encuadre, la decisión judicial adoptada puede verse intervenida por diversos agentes que varían de un funcionario a otro, lo cual puede restar certeza al justiciable.

- Sabemos que los litigios quedan confiados a los criterios que tenga cada juez; por ello, la importancia de que la capacitación judicial sea integral y que se haga énfasis en el nuevo sistema de valoración probatoria al mismo tiempo que los jueces conozcan estos procesos mentales que todos los seres humanos experimentamos. Para ejercer ese alto encargo, siempre ha sido necesario poseer capacidad racional y emocional. Pues bien, en la búsqueda de soluciones justas, nos encontramos ante la necesidad de tomar conciencia de cargas afectivas, designios anticipados o prevenciones en favor o en contra de alguien que pueden influir en la decisión judicial, debido a que ellos pueden considerarse como los principales obstáculos para actuar dando un debido cumplimiento a los principios de presunción de inocencia, igualdad ante la ley, igualdad entre las partes, imparcialidad y presunción de inocencia, desde un análisis subjetivo. Esto en razón de que desde el instante en que se categoriza o se impone una etiqueta a las personas implicadas en un asunto legal, estas portan una carga o valor agregado que será difícil dejar fuera de la resolución judicial.

- Habiendo advertido que el funcionario judicial no es una persona insensible ni su proceso decisional se da de manera autómata, la encomienda está en que el juzgador sea capaz de anticipar circunstancias y aspectos del caso que pueden participar de su decisión, a efecto de matizar el efecto que estos influjos puedan tener en su fallo. En otras palabras, para la correcta administración de justicia, será imprescindible que el juzgador pueda resolver esta categoría heurística.

- La piedra angular de un juicio justo es la imparcialidad del juez, pues es esta la que genera la confianza en la justicia por parte de la ciudadanía. Luego, entonces, para sostener y fomentar esa confianza, el juez debe de evitar caer en la riesgosa posición de formar su convicción y emitir un fallo alejado de los puntos litigiosos y que encuentre sustento en influencias extrañas al derecho. En efecto, al juzgar, la intuición y el sentimiento tienen muy frecuentemente una participación más importante de lo que a primera vista parece. Reconocer que existen sesgos cognitivos y en todo caso las proyecciones a las que ningún juez, ni el más severo, puede sustraerse, le permitirá juzgar o proceder con rectitud, sin vulnerar la imparcialidad que su alto oficio reclama.

- Después de las ideas expuestas, no podemos dejar de enfatizar que en la actualidad y con la próxima implementación del nuevo sistema de justicia penal en toda la República mexicana, es imprescindible reconocer que la tarea de impartir justicia es un asunto multidisciplinar, al que están llamadas a participar todas las ciencias que 
puedan aportar teoría, tecnología y técnicas para así subsanar las carencias a las que como individuos o como grupos estamos destinados.

\section{BIBLIOGRAFÍA}

Beltrán, E. y VArgas, N. (1993). "Psicología jurídica y criminología”, en Ardila, R. (comp). La Psicología en Colombia. Bogotá: Tercer Mundo.

Calamandrei, P. (2009). Elogio de los jueces escrito por un abogado. Editorial Reus.

Galván Castañeda, M. (2008). “El Campo de la Psicología Jurídica”, en L. Muñoz Sabaté, R. Bayés, y F. Munné, Introducción a la Psicología Jurídica. México: Trillas.

García-Lopez, E. (2010). Fundamentos de Psicología Jurídica y Forense. México: Oxford.

García-LóPEZ,E. (2014). Psicopatología forense. Bogotá: Editorial Manual Moderno.

García-LóPez, E.; LacAlle, J. y Pérez-Marqués, A. (2006). “Psicología jurídicaforense y juicios orales en materia penal: Perspectivas, riesgos y desafíos", en Jus Semper Loquitur.

GARCÍA BAEZA, E. (2014). "El juzgador y los retos prácticos del sistema penal acusatorio en las audiencias", en Revista digital de la reforma penal, año III, número 9, México.

Hernández, G. (2011). Psicología jurídica iberoamericana. Bogotá: Editorial Manual Moderno.

Mixán Mass, F. (1991). La prueba en el procedimiento penal. Lima: Edit. Ediciones Jurídicas.

Quintero, L. y LóPez, E. (2010). "Psicología Jurídica: quehacer y desarrollo", en Diversitas: perspectivas en psicología, vol. 6, n. ${ }^{\circ} 2$.

Muñoz Aranguren, A. (2012). “A propósito de ciertas resoluciones judiciales. Los sesgos cognitivos y el Derecho: el influjo de lo irracional”, en La Opinión, marzoabril 2012.

Muñoz Aranguren, A. (2011). "La influencia de los sesgos cognitivos en las decisiones jurisdiccionales: el factor humano. Una aproximación”, en Revista para el análisis del derecho. Barcelona: Indret, abril 2011. 
Muñoz Sabaté, L.; Bayés, R. y Munné, F. (2008). Introducción a la Psicología Jurídica. México: Trillas.

PÁsARA, L. (2012). Cómo sentencian los jueces del Distrito Federal en materia penal. México: Universidad Nacional Autónoma de México.

Rodríguez Manzanera, L. (2000). Penología. México: Porrúa.

Rocha LiceA, L. (2014). “La función del juez en el nuevo sistema de justicia penal acusatorio. La función del juzgador en el Sistema Procesal Penal Acusatorio Adversarial", en Nova Iusticia, Revista digital de la reforma penal, año III, número 9, México, noviembre 2014.

SCHMIDT, V. y FIRPO L. (2010). “Modelo psicobiológico de personalidad de Eynsenck: una historia proyectada hacia el futuro", en Revista internacional de psicología, vol $11,{ }^{\circ}{ }^{\circ}$, julio 2010 .

Soria Verde, M.A. y SÁiz RocA, D. (2006). Psicología criminal. Madrid: Pearson.

Velasco Díaz, C. (2014). "La psicología aplicada a la investigación criminal, La autopsia psicológica como herramienta de evaluación forense", en Revista Electrónica de Ciencia Penal y Criminología.

Vera Vega, J. (2011). “Algunas notas sobre la relación entre derecho penal y psicología a la luz de la prueba de los elementos subjetivos del delito", en Revista de Psicología. 